\title{
Molecular regionalization of the diencephalon
}

\author{
Almudena Martinez-Ferre and Salvador Martinez *
}

Instituto de Neurociencias, UMH-CSIC, Alicante, Spain

\section{Edited by:}

Steffen Scholpp, Karlsruhe Institute of

Technology, Germany

\section{Reviewed by:}

Tomomi Shimogori, RIKEN Brain

Science Institute, Japan

Thomas Mueller, University of

Freiburg, Germany

Matthias Carl, University Heidelberg,

Germany

\section{${ }^{*}$ Correspondence:}

Salvador Martinez, Instituto de

Neurociencias, UMH-CSIC, Campus

de San Juan, 03550-San Juan,

Alicante, Spain.

e-mail:smartinez@umh.es
The anatomic complexity of the diencephalon depends on precise molecular and cellular regulative mechanisms orchestrated by regional morphogenetic organizers at the neural tube stage. In the diencephalon, like in other neural tube regions, dorsal and ventral signals codify positional information to specify ventro-dorsal regionalization. Retinoic acid, Fgf8, BMPs, and Wnts signals are the molecular factors acting upon the diencephalic epithelium to specify dorsal structures, while Shh is the main ventralizing signal. A central diencephalic organizer, the zona limitans intrathalamica (ZLI), appears after neurulation in the central diencephalic alar plate, establishing additional antero-posterior positional information inside diencephalic alar plate. Based on Shh expression, the ZLI acts as a morphogenetic center, which cooperates with other signals in thalamic specification and pattering in the alar plate of diencephalon. Indeed, Shh is expressed first in the basal plate extending dorsally through the ZLI epithelium as the development proceeds. Despite the importance of ZLI in diencephalic morphogenesis the mechanisms that regulate its development remain incompletely understood. Actually, controversial interpretations in different experimental models have been proposed. That is, experimental results have suggested that (i) the juxtaposition of the molecularly heterogeneous neuroepithelial areas, (ii) cell reorganization in the epithelium, and/or (iii) planar and vertical inductions in the neural epithelium, are required for ZLI specification and development. We will review some experimental data to approach the study of the molecular regulation of diencephalic regionalization, with special interest in the cellular mechanisms underlying planar inductions.

Keywords: diencephalon, ZLI, Shh

\section{INTRODUCTION}

The formation of the neural tube, a process called neurulation, requires a precise combination of inductive signals from local signaling centers, the primary organizers (e.g., the node and anterior visceral endoderm), which regulate the polarity of the embryo and brain primordium growth. These signals code positional information that, at the cellular level, is translated into differential proliferation and intercalative cell movements (Sanchez-Arrones et al., 2012), which finally will define the regional morphogenesis of the neural epithelium. Once the neural tube is formed, secondary organizers refine the histogenesis of the brain primordium, governing forebrain, midbrain and hindbrain regional and sub-regional differentiation (Jessell and Sanes, 2000; Colas and Schoenwolf, 2001). Morphogenetic signals in the prosencephalon are molecules that belong to four genetic families: Wingless-Int protein family (Wnt; Dickinson and McMahon, 1992), Hedgehog family (Hh; Echelard et al., 1993), Bone morphogenetic protein family (Bmp; Kingsley, 1994) and Fibroblast growth factor family (Fgf; Crossley and Martin, 1995), which confer positional identity to different cellular populations distributed in compartments or domains along the neural tube wall. The temporo-spatial distribution of these signals at early developmental stages is therefore crucial for the governing brain morphogenesis and neural fate specification.

\section{REGIONALIZATION OF THE NEURAL TUBE: LONGITUDINAL AND TRANSVERSE ORGANIZATION}

Early after neurulation, three primary vesicles in the anterior neural tube can be observed. These are known as the forebrain (prosencephalon), which becomes subdivided into the anterior secondary prosencephalon (telencephalon, optic vesicles, and hypothalamus) and the diencephalon (revised in Martinez et al., 2012); caudally we have the midbrain (mesencephalon) and hindbrain (rhombencephalon), which continued caudally with the spinal cord.

In the last century, embryologists interpreted the localization and developmental significance of anatomical reliefs in the neural tube wall (bulges, ventricular furrows, and ridges) in different ways. Two major morphological paradigms emerged and have competed for primacy to interpret the morphogenetic processes underlying neural plate and tube regionalization (see for extensive reviews Nieuwenhuys, 1998, 2011; Puelles, 2001; and citations therein). Since these interpretative discrepancies have been especially evident in diencephalic patterning, we will review some relevant assumptions and conclusions postulated in each one to understand diencephalic development. On the one hand, the columnar paradigm, instituted by Herrick (1910), is a regional-topographic model that distinguishes four superposed longitudinal diencephalic domains or columns (AlvarezBolado et al., 1995; Swanson, 2003) called from dorsal to ventral 
direction: epithalamus, thalamus, ventral thalamus, and hypothalamus. These divisions extend functional columns of the mesencephalon and rhombencephalon into the prosencephalon. In this model the brain axis ends in the telencephalon and passes longitudinally through the hypothalamus, which is conceived to be a ventral part of the diencephalon. On the other hand, we have the prosomeric model, originally postulated by Bergquist (1932), and recently revised by Rubenstein et al. (1994) and Puelles and Rubenstein (2003), which is a widely accepted interpretational paradigm to compare anatomical, molecular (gene transcription patterns), and experimental data. Interestingly, homeobox-gene expression patterns and lineage restriction experiments also support the notion that prosomeres are developmental entities (segments; Scholpp and Lumsden, 2010; Puelles et al., 2012).

Gene expression patterns reveal neuroepithelial boundaries that segregate cell domains with similar molecular properties. Thus, the diencephalon can be subdivided into four longitudinal columnar territories, which from ventral to dorsal are the floor plate, basal plate, alar plate, and roof plate (which are also present along the whole neural tube); and into three transverse segments or prosomeres (prethalamus or $\mathrm{p} 3$, thalamus or $\mathrm{p} 2$, and pretectum or $\mathrm{p} 1$, from anterior to posterior). Caudal segments where called mesomeres, in the mesencephalon, and rhombomeres, in the rhombencephalon (Nieuwenhuys, 1998, 2011; Puelles, 2001). In the prosomeric model hypothalamus and telencephalon are respectively the basal and alar derivatives of the most anterior neural region: the secondary prosencephalon. In contrast, in the columnar model: (i) the hypothalamus is classified together with ventral thalamus as anterior diencephalon and represents the ventral diencephalic column; and (ii) the telencephalon is conceived as the rostral continuation of dorsal diencephalic columns (also classified as caudal diencephalon; Swanson, 2003; Figure 1A). Throughout this review, we follow the prosomeric interpretation and treat the hypothalamus as a basal plate derivative of the secondary prosencephalon and not as a part of the diencephalon.

Therefore, the prosomeric model proposes that dorso-vental (DV) and antero-posterior (A-P) patterning subdivides the neural tube into distinct neuroepithelial fields: segments and columns, which are respectively separated by transversal and longitudinal boundaries. Morphogenetic information coded by inductive signals defines locally specific patterns of genetic expressions in these territories. Gain- and loss-of-function experiments, together with gene expression data, support the idea that: (1) lateral (dorsal) signaling is regulated by members of the TGF- $\beta$ superfamily, such as Bmp4 and Bmp7, and by Wnt family members (Basler et al., 1993; Dickinson et al., 1995; Liem et al., 1995; Shimamura and Rubenstein, 1997; Lee and Jessell, 1999), (2) patterning of the ventral part is regulated mainly by Shh and Nkx2.2 (Price et al., 1992; Echelard et al., 1993; Shimamura et al., 1995), and finally, (3) antero-posterior patterning (A-P) is regulated by signaling centers identified at various boundary regions in the vertebrate neural tube (revised in Martinez, 2001; Echevarria et al., 2003; Vieira et al., 2010). These A-P signaling centers, also known as secondary organizers, are: the anterior neural ridge (ANR) at the anterior end of the neural plate/tube (Houart et al., 1998), the zona limitans intrathalamica (ZLI) in the middle of the diencephalon (Larsen et al., 2001; Echevarria et al., 2003), and the

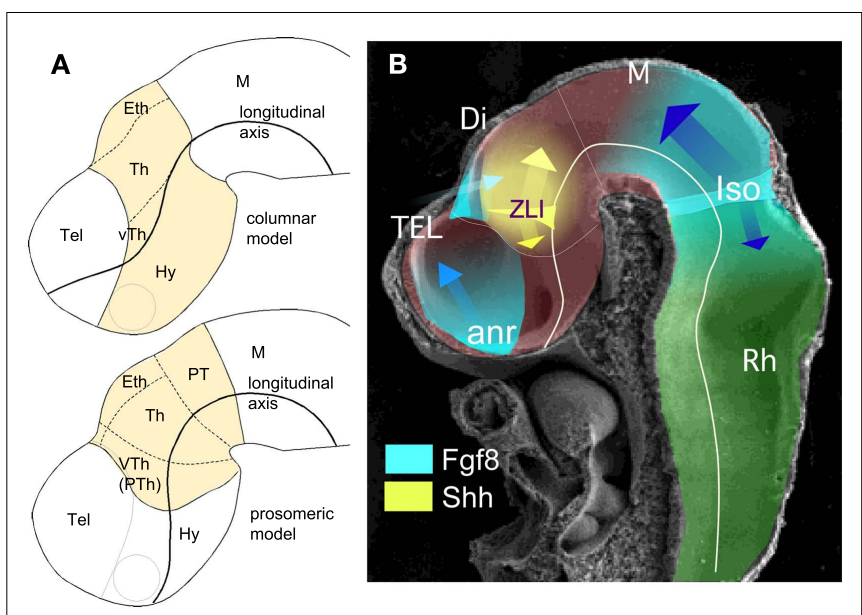

FIGURE 1 | (A) Schematic representations of a lateral view of E10.5 mouse neural tube where diencephalic territories (yellow) have been represented following columnar (above) and prosomeric (below) models. (B) Scanning electron microscope image showing a lateral view of E10.5 mouse neural tube where the main neural segments and planar secondary organizers are represented. Abbreviations: anr, anterior neural ridge; Di, diencephalon; Eth, epithalamus; $\mathrm{Hy}$, hypothalamus; IsO, isthmic organizer; $\mathrm{M}$, mesencephalon; PT, pretectum; Rh, rhombencephalon; Tel, telencephalon; Th, thalamus; VTh (PTh), ventral thalamus (prethalamus); ZLI, zona limitans intrathalamica.

isthmic organizer ( $\mathrm{IsO}$ ) at the mid-hindbrain boundary (Crossley et al., 1996; Figure 1B). Although the molecular nature of signals may be different in each one of these secondary organizers, they share common basic characteristics: (i) organizers are a source of signaling molecules that codify positional information specifying cellular identities in neighboring regions, and (ii) this molecular information regulates the expression of other genes, mainly transcription factors, conferring specific cell fate properties to neuroepithelial cells. The combination of medio-lateral and antero-posterior inductive influences generates a $2 \mathrm{D}$ gridlike organization that is transformed, by the developmental time and morphogenetic movements, into a 3D framework translating the molecular code (positional information) into brain structure. We could consider that the evolutionary advantage of segmentation resides in its modular structure, distributing cell populations into functional units (Davis and Patel, 1999; Ten Tusscher and Hogeweg, 2011), which show properties of morphogenetic fields: developmental autonomy and potential of histogenetic regulation (revised by De Robertis et al., 1991).

\section{PATTERNING AND HISTOGENESIS OF THE DEVELOPING DIENCEPHALON}

At each stage of development, the expressed genes in a neural region represent the state of its molecular specification. Thus, these gene expression patterns characterize the regional subdivisions (or molecular regionalization) of the brain, by regulating the main histogenetic processes such as proliferation, migration, differentiation, and establishment of neuronal connections. The final result of the neural regionalization is the establishment of anatomical regions with specific programs of structural and functional maturation. 
The prosomeric diencephalon (or caudal diencephalon) is a complex region in the central area of the vertebrate brain, located between the secondary prosencephalon and the midbrain (Figure 1A). The morphologic segmentation in the mouse diencephalon starts at E9.5 (corresponding to HH14 in chick embryos) and continues during the next 2-3 days. At E10-11 (HH19 in chick embryos), the diencephalic prosomeres are morphologically apparent as ventricular ridges and lateral wall bulges (Puelles, 2001). Then, diencephalic regionalization progresses when the expression of several genes into defined alar or basal territories (as is the case for $W n t 3 a, G b \times 2$, and Sox14) precedes the histogenesis of prethalamic (p3), thalamic (p2), and pretectal (p1) nuclear masses in the alar plate, as well as segmental-corresponding domains (p3-, p2-, and p1-teg; Figures 2 and 3) in the basal plate. At E12.5 (HH28 in chick embryos), the diencephalon presents a complete segmental structure (Figure 3A; Puelles et al., 2008, 2012; Suzuki-Hirano et al., 2010).

Morphological and experimental data showed a discontinuous neurogenic pattern in the diencephalon at neural tube stage, developing the concept of migration areas, by Bergquist and Kallen (1954), and neurogenic territories by Puelles et al. (1987), in agreement to segmental theories and against prevalent interpretations of functional columns in brain morphogenesis. For instance, Altman and Bayer (1988a,b,c, 1989a,b,c) interpreted cell birthdates and topography of thalamic nuclei as relevant information to determine progenitor position in the neuroepithelium, postulating a lobular model of diencephalic patterning under the columnar framework. Recent work analyzing molecular identities of neuroepithelial progenitors, together with the establishment of topological references and experimental embryology approaches generated new evidences in favor of the prosomeric interpretation of diencephalic patterning. Actually, studies using scanning electron microscopy and clonal analysis after neuroepithelial labeling on chick embryos, led Figdor and Stern (1993) to subdivide the diencephalon into four transverse domains called diencephalic neuromeres (D1-D4). Later on, studies based upon expression profiles of transcription factors and immunocytochemical staining for cell adhesion molecules confirmed and extended the segmental character of diencephalic alar plate in chick and mouse embryos (reviewed in Simeone et al., 1992; Larsen et al., 2001; Kataoka and Shimogori, 2008). It is now widely accepted that the diencephalon is formed by three prosomeres subdivided into alar and basal plate portions. We have already described these diencephalic units as prosomere $1(\mathrm{p} 1)$, prosomere 2 ( $\mathrm{p} 2$ ), and prosomere 3 (p3; Puelles and Rubenstein, 2003). These units comprise the following structures in their alar and roof plates: the pretectum ( 1 1), the thalamus and epithalamus (which contains the habenula and the pineal gland; p2), and the prethalamus and prethalamic eminence (p3). In their basal plates, these prosomeres contain structures that are classified as retromammillary area and prerubral tegmentum in mammals and birds, and posterior tubercular structures in anamniotes like Xenopus and zebrafish (Bergquist, 1932; Puelles et al., 1996, 2007, 2012; Wullimann and Puelles, 1999; GarciaLopez et al., 2004; Osório et al., 2010; Martinez et al., 2012; Figures 2B-D and 3A).

\section{STRUCTURAL ORGANIZATION AND FUNCTION OF THE DIENCEPHALON}

The diencephalon functions as a relay structure that receives and filters afferent sensory information, relaying it on to the cerebral cortex.

As we have described previously, during embryogenesis each diencephalic division can be characterized by the expression of specific genes, coding for regulatory proteins, morphogenetic molecules or other molecular markers (Puelles et al., 1987; Puelles and Rubenstein, 1993; Stoykova and Gruss, 1994; Redies, 1995; Redies et al., 2000; Kataoka and Shimogori, 2008; Suzuki-Hirano et al., 2010). Neurons are born in the ventricular epithelium and migrate to the mantle layer, where they aggregate into thalamic nuclei at different radial distances creating periventricular, intermediate, or superficial nuclear masses, which are connected through axonal fibers in order to integrate functional systems.

\section{PROSOMERE 1: PRETECTUM}

In birds Rendahl (1924) and Keyser (1972), distinguished two subdivisions in the pretectum. The rostral p1 is known as precommissural pretectum (PTp), extends in front of the posterior commissure and behind the $\mathrm{p} 2$ where the retroflex tract follows $\mathrm{p} 2 / \mathrm{p} 1$ limit. The caudal subdivision of $\mathrm{p} 1$ is related to the posterior commissure, and it is known as commissural pretectum (PTc). Later, a third subdomain was described between the commissural and precommissural pretectum, which was called yuxta commissural pretectum (PTy; Puelles et al., 1996; Redies et al., 1997). Additional studies on cadherins expression in the avian diencephalon (Redies and Takeichi, 1996; Redies, 2000; Puelles et al., 2007) and immunohistochemical studies with anti-calbindin and anti-calretinin in mammals (Martinez and Puelles, 2000) supported these three subdivision of the $\mathrm{p} 1$ alar plate. Recently, an exhaustive analysis of pretectal molecular regionalization and histogenesis (or genoarchitecture) has been developed by Luis Puelles' group in chick embryos (Ferran et al., 2008, 2009), extending pretectal molecular regionalization up to nuclear organization. Pretectal structures are involved in the regulation of the information coming from the visual system and the establishment of visual reflexes.

Basal structures in $\mathrm{p} 1$ include: the anterior pole of ventral tegmental area (VTA) and substance nigra (SN; Puelles et al., 2004, 2007, 2012), which are involved in controlling movement, as well as the interstitial nucleus of Cajal (IC), which is functionally involved in head orientation reflexes (Garcia-Lopez et al., 2004; Figure 3A).

\section{PROSOMERE 2: THALAMUS AND EPITHALAMUS}

The thalamus and epithalamus (habenula and pineal gland) are the alar P2 derivatives. Alar p2 generates the thalamic nuclear complex (Figure 3A). It has been recently classified as caudal thalamus and subdivided into rostral (cTh-R) and caudal (cTh-C) subdomains in relation to differential expression patterns of developmental genes in mouse embryos (Blackshaw et al., 2010; Shimogori et al., 2010). In addition to the function as a relay of the sensorial information in its way to the cortex, the thalamus, together with the basal ganglia, and the cerebellum, is neutrally linked to the 


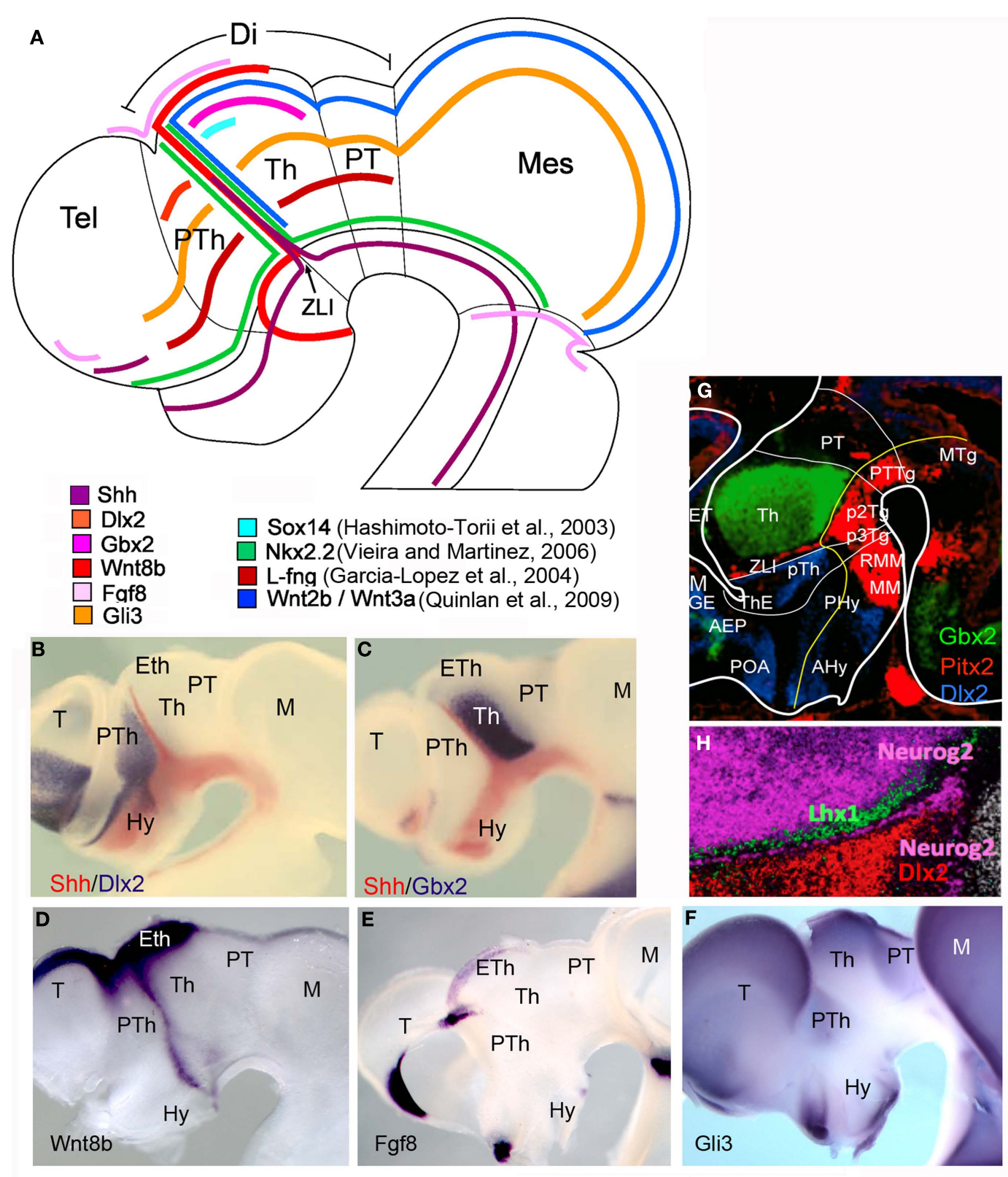

FIGURE 2 | Schematic representation and in situ hybridization showing expression pattern of genes expressed in the $\mathrm{ZLI}$ and in its neighboring regions in chick $(A-F)$ and mouse $(\mathbf{G}, \mathbf{H})$ embryos. Different colors

represent the expression of different genes. Gene symbol and color codes are identified in each diagram. (A) Schematic representation of the planar expression patterns of the principal genes codifying for signaling molecules and transcription factors in the diencephalon, located on a chick embryo schema at stage $\mathrm{HH} 23$. (B-F) Whole mount in situ hybridization in chick embryos showing the expression of genes in the diencephalon. $\mathbf{( G , H ) ~ L a t e r a l ~}$ view of mouse embryo sagittal sections showing in situ hybridization at E14.5 (from www.eurexpress.org). Note the expression of Pitx2 in the ZLI. Lhx 1 is expressed in the p2 ZLI, while Neurog2 is expressed in the p1 ZLI. Abbreviations: $\mathrm{AEP}$, anterior entopeduncular area; $\mathrm{AHy}$, anterior hypothalamus: Di, diencephalon; Eth, ET, epithalamus; Hy, hypothalamus; M, Mes, mesencephalon; MGE, medial ganglionic eminence; $\mathrm{MM}$, mammillary region; MTg, mesencephalic tegmentum; Pal, pallium; PHy, posterior hypothalamus; POA, preoptic area; PT, pretectum; PTh, pTh prethalamus; PTTg, pretectal tegmentum; P3Tg, prosomer 3 tegmentum; P2Tg, prosomer 2 tegmentum; RMM, retromammillary región; Tel, telencephalon; Th, T thalamus; ThE, thalamic eminence; ZLI, zona limitans intrathalamica. cerebral motor cortex in reciprocal or feedback fashion regulating, modifying, and fine-tuning motor functions.

The epithalamus located dorsally in $\mathrm{p} 2$, extends rearward from the thalamus and it holds the habenular nuclei, the stria medullaris tract and the pineal body. The habenular nuclei play a role in motor and cognitive actions by means of dopaminergic-mediated mechanisms in the striatum, as well as emotional responses. Habenular efferences to the interpeduncular nucleus in the hindbrain 


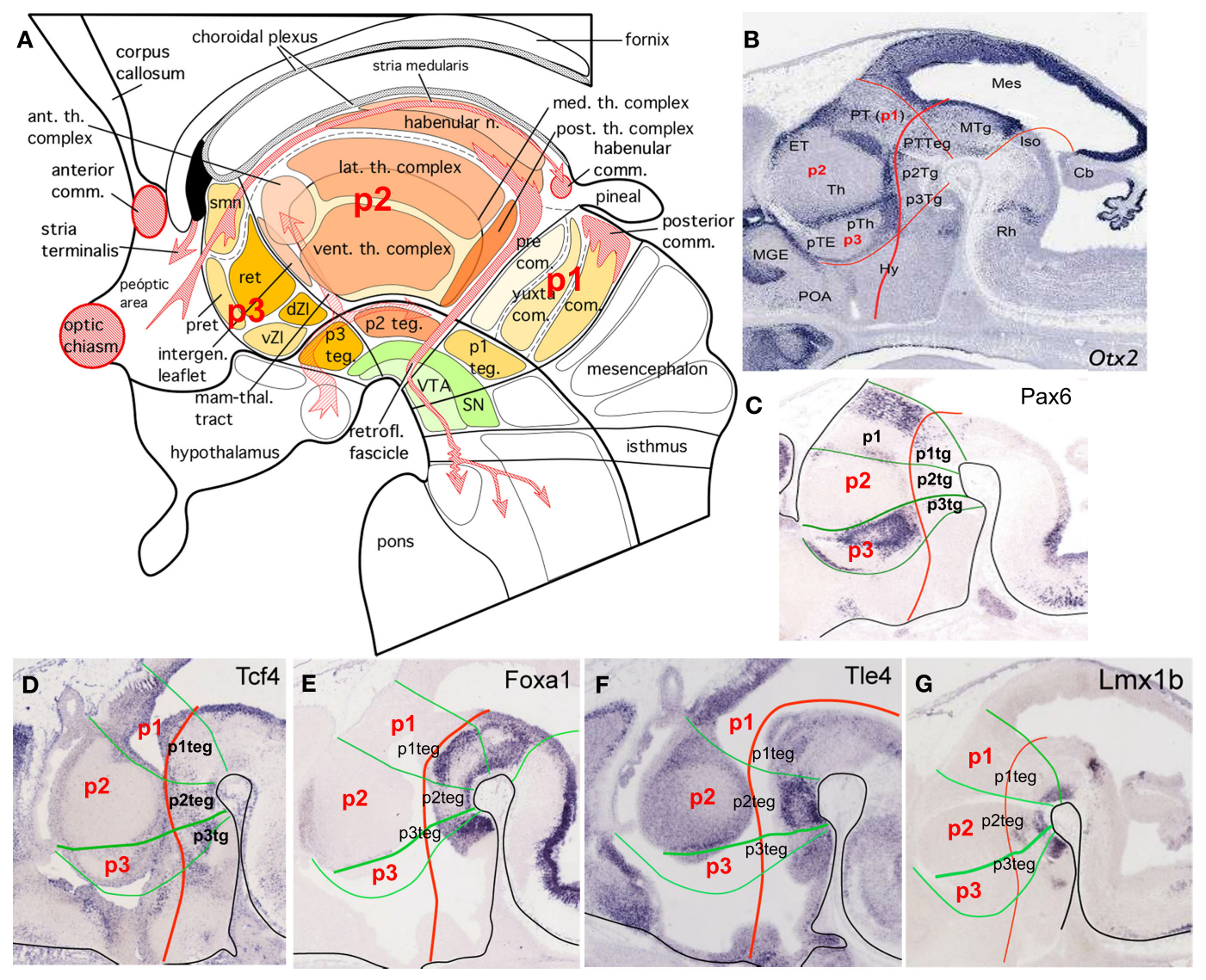

FIGURE 3 | (A) Schematic representation that summarizes the different nuclei and structures in the mammalian diencephalon. Major nuclear subdivisions of alar and basal plate and the main axonal tracts, which cross the three domains of the diencephalon, are also represented (modified from Puelles et al., 2008). (B-G) Expression patterns of several genes defining the different compartments of the diencephalon at E14.5 (Eurexpress). Otx2, orthodenticle homeobox 2 is expressed in the boundary between the embryonic thalamus and prethalamus, in the boundary between the pretectum and thalamus, in the p3 zona incerta and in the liminal part of the alar p2.; Pax6, paired box 6 is expressed in the commissural pretectum and in the prethalamus; Tcf4, transcription factor 4 is expressed in the ventricular epithelium of the alar and basal diencephalon; Foxa1, forkhead box A1 is expressed in the basal plate of the diencephalon; Tle4, transducin-like enhancer of split 4 is expressed strongly in the mantle layer of the p2 basal plate and weakly in the mantle layer of the prethalamus, epithalamus, and pretectum; Lmx1b, LIM homeobox transcription factor 1-beta is expressed in the basal plate of the diencephalon. Abbreviations: Ant. th. complex, anterior thalamic complex; Anterior comm., anterior commissure; $\mathrm{Cb}$, cerebellum; Com., commissural pretectum; dZI, dorsal zona incerta; ET, epithalamus; Habenular comm., habenular commissure; Habenular n., habenular nucleus; Hy, hypothalamus; Intergen leaflet, intergeniculate leaflet; Iso, isthic organizer; Lat. th. complex, lateral thalamic complex; Mam-thal. tract, mammillo-thalamic tract; Med th. complex, medial thalamic complex; Mes, mesencephalon; MGE, medial ganglionic eminence; MTg, mesencephalic tegmentum; p1, prosomer 1; p2, prosomer 2; $\mathrm{p} 3$, prosomer 3; p1-teg (p1Tg), prosomer 1 tegmentum; p2 teg (p2Tg), prosomer 2 tegmentum; p3 teg (p3Tg), prosomer 3 tegmentum; Post. th. complex, posterior thalamic complex; Posterior comm., posterior commissure; Precom., precommissural pretectum; Pret, prethalamus; PT, pretectum; pTE, prethalamic eminence; pTh, prethalamus; PTTeg, pretectal tegmentum; Ret, reticular nucleus; Retrofl. fascicle, retroflex fascicle; Smn, stria medullaris; SN, substantia nigra; Th, thalamus; vZI, ventral zona incerta; VTA, ventral tegmental area; Yuxtacom., yuxta commissural pretectum. formed the retroflexus tract, very well characterized in mouse and zebrafish (Aizawa et al., 2005; Hikosaka et al., 2008; Matsumoto and Hikosaka, 2008, 2009). The pineal gland or epiphysis, remnant of an ancient and complex light-sensitive system, controls the circadian internal clock by secreting melatonin (Falcón et al., 2009). Moreover, other processes controlled by the epithalamus are: pain processing and stress responses (Andres et al., 1999).

The thalamic nuclei are named and classified in mammals according to their positions within the thalamus and by their function (Figure 3A; Puelles et al., 2007). According to their topographic position, the thalamic nuclei are detailed as follows (Jones, 2006; Puelles et al., 2012). The anterior nuclei (AN) of thalamus are collection of nuclei at the rostral pole of the thalamus (the caudal thalamus by Kataoka and Shimogori, 2008; Shimogori et al., 2010), playing a role in modulation of alertness, as well as in learning and memory (Jones, 2006; Puelles et al., 2012). The ventral anterior (VA) and ventral lateral (VL) thalamic nuclei are involved with motor function. The ventral posterior nucleus, posterolateral, and posteromedial (VPL, VPM) are relating to the sensorial systems. The medial dorsal thalamic nuclei (MD) are involved with emotional arousal and the expression of emotionally based behavior, as well as memory and feelings of pleasure. Furthermore, the intramedular and centromedian thalamic nuclei $(\mathrm{CM})$ regulate excitability levels within the cerebral cortex playing a major 
role in arousal and alertness in tune with the circadian rhythm. Moreover, impulses from the auditory structures synapse in the medial geniculate thalamic nuclei (MGN), where they are sent to the auditory centers of the cerebral cortex. Finally, impulses from the ganglion cells in the retina, via the optic nerves, synapse in the lateral geniculate thalamic nuclei (LGN), where visual information is processed and sent on to the visual areas of the cerebral cortex.

Basal derivatives are the interstitial rostral nucleus (IR), involved in visual orientation reflexes, and the most anterior areas of the VTA and the substantia nigra (SN; Garcia-Lopez et al., 2004; Puelles et al., 2004, 2007, 2012), together with other reticular populations in the basal plate (Figure $\mathbf{3 A}$ ).

\section{PROSOMER 3: PRETHALAMUS AND PRETHALAMIC EMINENCE}

The prethalamus (formerly ventral thalamus) is a heterogeneous constellation of nuclear groups, which have been molecularly well defined in mouse (Shimogori et al., 2010; Puelles et al., 2012), in chicken (Garcia-Lopez et al., 2004), in zebrafish (Wullimann and Puelles, 1999; Mueller et al., 2006; Staudt and Houart, 2007), and in Xenopus (Bachy et al., 2001; Domínguez et al., 2010). The reticular thalamic nucleus $(\mathrm{Rt})$, ventral lateral geniculate nucleus (VLG), subgeniculate nucleus (SG), and zona incerta (ZI), are the main prethalamic derivatives. In addition the intergeniculate leaflet (IGL), together with the caudal pole of VLG represent the derivatives of ZLI progenitors (Delaunay et al., 2009), and have been grouped as derivatives of the ZLI and anterior p2 domain (or rostral part of the caudal thalamus cTh-R) which is dependent on Fgf8 signaling (Kataoka and Shimogori, 2008; Shimogori et al., 2010). The major feature of prethalamic connections is the lack of projections to the cerebral cortex. Unlike the thalamus, it develops efferent connections to the striatum, red nucleus, and substantia nigra. Moreover, Rt, VLG, SG, and ZI connect with other thalamic nuclei, modulating all incoming and outgoing information of the dorsal thalamus. The IGL receives direct retinal afferences and is connected with the suprachiasmatic nuclei, which is important for circadian regulation (Puelles et al., 2007).

Furthermore, other alar structures in the p3 include: the prethalamic eminence (PThE) located dorsally to the prethalamus and the choroid plexus $(\mathrm{cpx})$ in the roof plate. This region represents in $\mathrm{p} 3$ the anterior extension of epithalamus. They develop nuclear masses functionally related with the stria medullaris nuclei, which are directed related to habenular nuclei and its function, as well as dispersed cellular intermingled with axonal fibers in the telencephalic peduncle (as perireticular and entopeduncular complex; Wullimann and Muller, 2004), which play axonal guidance properties of thalamo-cortical projections during development (Mitrofanis and Baker, 1993; Ulfig et al., 2000).

The retromammillary region represents $\mathrm{P} 3$ basal plate (GarciaLopez et al., 2004; Figure 3A).

\section{MOLECULAR ORGANIZATION OF THE DIENCEPHALON}

Over the last two decades, the discovery of regulatory genes expressed with regionally restricted patterns in the developing diencephalon provided experimental results that allowed to develop causal predictions of the diencephalic organization (Figures 2 and 3 ).
At initial stages of mouse forebrain development, diencephalic regionalization was identified by the expression of some molecular markers such as Otx2, Six3, or Pax6 (Simeone et al., 1992; Oliver et al., 1995). After neurulation, the expression of a considerable numbers of genes coding for signaling molecules and transcription factors reveal the longitudinal and transverse patterning of the diencephalon. In the diencephalic roof plate of chick and mouse embryos, while Wnt1 is expressed in the dorsal midline of pretectum and epithalamus up to the choroidal plexus tenia (Bach et al., 2003), Wnt8b expression is restricted to the prethalamic eminence and telencephalic pallium (Parr et al., 1993). Moreover, in chick embryos, Wnt $8 b$ is also expressed in the ZLI (Garda et al., 2002). In the diencephalic alar plate, Pax6 is expressed initially throughout the alar forebrain domains, stopping caudally at the p1-mesencephalic boundary (Stoykova and Gruss, 1994), though its expression is downregulated both in rostral and caudal epithelium to ZLI (the central diencephalic organizer that express Shh morphogenetic signal). At later stages, Pax6 is restricted to the rostral half of the prethalamus and the caudal pretectum (Figure 3C). In the prethalamus, Dlx genes were expressed (Figures 2B,G,H; Bulfone et al., 1993). Moreover, Wnt $3 a$ and Fgf15 defines the entire alar plate of p2 (thalamus and epithalamus), whereas $G b \times 2$ and Sox14 are expressed in the thalamic domain but not the epithalamus (Figures 2C,G; Bulfone et al., 1993; Martinez-de-la-Torre et al., 2002; Gimeno et al., 2003). The caudal limit of $G b \times 2$ expression domain (Figures $2 \mathrm{~A}, \mathbf{C}, \mathbf{G}$ ), together with the AP-2 (Chazaud et al., 1996) and Ebf-1/2/3 (Garel et al., 1997) gene expressions in p1 allows to establish the molecular boundary between $\mathrm{p} 1$ and $\mathrm{p} 2$. Actually, in zebrafish this boundary requires $L h \times 2 / 9$ expression and Wnt signaling to develop normally (Peukert et al., 2011). Nkx2.2 is expressed in the neural epithelium flanking the expression of Shh and Pitx2 in the ZLI (Figures 2A,G; Shimamura et al., 1995). Other genes regulated by the expression of Shh in the diencephalon are Gli genes, coding for transcription factors and mediating Shh signaling pathway. Gli1, Gli2 (activators of the Shh pathway), and Gli3 (inhibitor of Shh pathway) are expressed in the diencephalic alar plate (Figures 2A,F; HashimotoTorii et al., 2003). The homeodomain transcription factor Otx2 is expressed in the forebrain and midbrain with the caudal limit at the mid/hindbrain junction (Simeone et al., 1993). Later on during development, Otx2 is expressed in the ZLI and in the boundary between the pretectum and thalamus (Figure 3B).

Finally, basal plate epithelium show some regionally expressed genes; such as Tcf4, Foxa1, Tle4, Lmx1b, and Ptx2, revealing specific molecular domains in the diencephalic tegmental areas [Figures $2 \mathrm{D}$ and $3 \mathrm{D}-\mathrm{G}$; Eurexpress database (www.eurexpress.org); and Diez-Roux et al., 2011].

\section{THE ZONA LIMITANS}

\section{INTRATHALAMICA/MID-DIENCEPHALIC ORGANIZER}

Signaling molecules, such as fibroblast growth factor 8 (Fgf8), Sonic hedgehog (Shh), bone morphogenetic proteins (Bmps2, 4, 6, and 7), Wingless family (Wnts2b, 3a, 5a, and 7a), and retinoic acid, act as morphogenetic regulatory genes in the developing diencephalon. These molecules are produced by different diencephalic signaling centers and control the regional expression of transcription factors that code specific structural information. 
Among all these organizing zones, a central region in the diencephalon seems to be the master-signaling center controlling thalamic morphogenesis. This region is known as the ZLI, also called the mid-diencephalic organizer (MDO) by Scholpp and Lumsden (2010).

The ZLI is a neuroepithelial domain in the alar plate of the diencephalon, which separates the prethalamus from the thalamus (Figures 1 and 2). The ZLI is a conserved diencephalic landmark in vertebrate evolution, being described in amniotes and anamniotes, such as human, mouse, chick, zebrafish, and Xenopus embryos (Scholpp et al., 2006; Vieira et al., 2006; Domínguez et al., 2010; Gilbert, 2010). Neuroepithelial cells show clonal restriction inside ZLI territory and low proliferation rate (Puelles et al., 1987; Martinez and Puelles, 2000; Larsen et al., 2001). The expression of diverse genes coding for diffusible morphogens at the ZLI, especially Shh, underlies the current hypothesis that the ZLI may represent a diencephalic (thalamic) secondary organizer, which refine the identity and polarity of neighboring neuroepithelial regions (Figure 2; Rubenstein et al., 1994; Puelles et al., 1996; Nieuwenhuys, 1999; Martinez and Puelles, 2000; Vieira and Martinez, 2006).

\section{ZONA LIMITANS INTRATHALAMICA: EVIDENCES TO BE AN ORGANIZING CENTER}

The localization of neural organizers often correlates with the position of neuroepithelial boundaries between morphogenetic fields, usually identified by ventricular ridges in the neural tube, which also represent limits of intercalative cell movements through neuroepithelium (Figdor and Stern, 1993; Martinez and Puelles, 2000; Larsen et al., 2001; Garcia-Lopez et al., 2004). Experimental observations indicated that a region functions as an organizing center when it induced a different neuroepithelial fate in an ectopic neuroepithelial region. Thus, in reference to the $\mathrm{IsO}$, both, grafting experiments of IsO and implants of the Fgf8 beads, induced an ectopic and polarized mes-metencephalic fate in chick embryos, by re-patterning the host neuroepithelium (Crossley et al., 1996; Martinez et al., 1999; Sato and Joyner, 2009). Moreover, ablations of the isthmus (Irving and Mason, 1999) or genetic reduction of Fgf8 signal (Chi et al., 2003; Basson et al., 2008) triggered the reduction or the loss of the entire mesencephalon and rhombencephalon.

However, due to late activation and the dynamic process of Shh expression in the ZLI, potential inductive properties of ZLI presumptive territory in host tissue has not been yet observed after heterotopic transplantation (Vieira et al., 2006), probably because grafts should be performed in suitable regions and at the correct developmental stages.

\section{MECHANISMS REGULATING THE SPECIFICATION OF THE ZLI/GENE EXPRESSION AT THE MID-DIENCEPHALIC JUNCTION}

The cellular and molecular mechanisms that regulate the positioning and induction of Shh expression in the ZLI are not jet fully understood. However, this aspect could have evolutionary importance since gene expression differences have been reported between amniotes and anamniotes. For instance, in chick and zebrafish embryos, the mechanisms regulating the positioning and specification of the ZLI may be explained by the interaction between prechordal (Six3 positive) and epichordal (Irx3 positive) epithelium (Kobayashi et al., 2002; Braun et al., 2003; Scholpp et al., 2006; Vieira et al., 2006), which is a similar mechanism operating between $O t \times 2$ and $G b x 2$ at the mid-hindbrain boundary (Simeone et al., 1992; Wassarman et al., 1997). However, different molecular interactions should take part in mammals since Six3 activity is not required for the formation of maintenance of the ZLI (Lavado et al., 2008). In addition, other transcription factors expressed in the diencephalon, such as Fez/Fezl (in the prethalamic anlage) and Otx1/2 (in the ZLI and thalamus) have been postulated as necessary for establishing ZLI specification (Hirata et al., 2006; Jeong et al., 2006, 2011; reviewed by Scholpp and Lumsden, 2010). Moreover, we have demonstrated, in chick embryos, that the expression of $S h h$ in the basal plate is indispensable for the induction of Shh expression in the ZLI (Vieira and Martinez, 2006). In contrast, Scholpp et al. (2006) showed, in zebrafish embryos, that Shh expression remains in the ZLI even in a total absence of Shh expression in the basal plate, suggesting a potential requirement of a dorsal signal. Conversely, Shh expression in the ZLI is constrained by inhibitory factors derived from the dorsal diencephalon, since grafts of the dorsal diencephalic tissue inhibits ZLI propagation (Zeltser, 2005). In contrast to the whole induction of Fgf8 at the mid-hindbrain boundary, Shh expression in the ZLI is gradually extended form ventral to dorsal. However, in Fgf8 hypomorphic embryos, this initial basal activation of a morphogenetic signal in the IsO is also observed (see Figure 2 in Martinez-Ferre and Martinez, 2009). This suggests that the tissue closer to the basal plate is more sensitive to inductive signals or more permissive to the activation of $F g f 8$ in the Is $\mathrm{O}$, as it occurs in the ZLI in reference to Shh expression.

Wnt1 and Fgf8, two secreted factors normally expressed at the $\mathrm{IsO}$, mediate the morphogenetic activity of the isthmic neuroepithelial region. In the diencephalon, Shh has been demonstrated as possible effector molecule for the morphogenetic activity of the ZLI (Vieira et al., 2010) and promotes growth and differentiation of specific subdivisions of the thalamus and prethalamus (Vieira and Martinez, 2006; Szabó et al., 2009; Vue et al., 2009). Vieira and Martinez (2006) have demonstrated that Shh from the ZLI is necessary for nuclear organization in the diencephalon. Moreover, it is possible that other signaling molecules expressed in the ZLI or near this region, such as Fgf8 (Kataoka and Shimogori, 2008) or different Wnts (Wnt1, Wnt8b, Wnt3, and/or Wnt3a; Braun et al., 2003; Walshe and Mason, 2003; Garcia-Lopez et al., 2004; Quinlan et al., 2009), could be important for the diencephalic nuclear organization and cell survival (Mattes et al., 2012). In fact, Wnt family members, such as Wnt1 and $W n t 8 b$ are strong candidates for rostral patterning of the early neural plate in chick embryos (Chapman et al., 2004). Among them, Wnt8b is detected in the diencephalic alar plate in chick embryos at HH10 (Garda et al., 2002; Garcia-Lopez et al., 2004). Later in development, Wnt8b expression in the diencephalon generates a wedge-shaped area, flanked by lunatic-fringe ( $L$ - $f n g$ ) expression domains in the diencephalon (Larsen et al., 2001; Zeltser et al., 2001; Kiecker and Lumsden, 2005). Since Wnt8b expression in the ZLI is prior to Shh expression in this diencephalic region, it suggests that Wnt8b could be an indicator of the definitive ZLI localization. Altogether, 
we can conclude that the formation of the ZLI is regulated by multiple molecular and cellular factors.

\section{TOWARD AN INTEGRATIVE VIEW ON THALAMUS DEVELOPMENT AND ORGANIZATION}

The evolution of the brain occurs by neural changes that allow a group of organisms to develop a complex behavior and interact with the world in a unique way. Evolution is achieved through subsequent ontogenetic changes over times, which include modifications of some of the mechanisms involved during vertebrate brain development. Despite these inter-specific differences in brain development, basic conservative mechanisms during brain

\section{REFERENCES}

Aizawa, H., Bianco, I. H., Hamaoka, T., Miyashita, T., Uemura, O., Concha, M. L., Russell, C., Wilson, S. W., and Okamoto, H. (2005). Laterotopic representation of left-right information onto the dorso-ventral axis of a zebrafish midbrain target nucleus. Curr. Biol. 15, 238-243.

Altman, J., and Bayer, S. A. (1988a). Development of the rat thalamus: I. Mosaic organization of the thalamic neuroepithelium. J. Comp. Neurol. 275, 346-377.

Altman, J., and Bayer, S. A. (1988b). Development of the rat thalamus: II. Time and site of origin and settling pattern of neurons derived from the anterior lobule of the thalamic neuroepithelium. J. Comp. Neurol. 275, 378-405.

Altman, J., and Bayer, S. A. (1988c). Development of the rat thalamus: III. Time and site of origin and settling pattern of neurons of the reticular nucleus. J. Comp. Neurol. 275, 406-428.

Altman, J., and Bayer, S. A. (1989a). Development of the rat thalamus: IV. The intermediate lobule of the thalamic neuroepithelium, and the time and site of origin and settling pattern of neurons of the ventral nuclear complex. J. Comp. Neurol. 284, 534-566.

Altman, J., and Bayer, S. A. (1989b). Development of the rat thalamus: V. The posterior lobule of the thalamic neuroepithelium and the time and site of origin and settling pattern of neurons of the medial geniculate body. J. Comp. Neurol. 284, 567-580.

Altman, J., and Bayer, S. A. (1989c). Development of the rat thalamus: VI. The posterior lobule of the thalamic neuroepithelium and the time and site of origin and settling pattern of neurons of the lateral geniculate and lateral posterior nuclei. J. Comp. Neurol. 284, 581-601.

Alvarez-Bolado, G., Rosenfeld, M. G., and Swanson, L. W. (1995). Model of forebrain regionalization based on spatiotemporal patterns of POU-III homeobox gene expression, birthdates, and morphological features. J. Comp. Neurol. 355, 237-295.

Andres, K. H., Von Düring, M., and Veh, R. W. (1999). Subnuclear organization of the rat habenular complexes. J. Comp. Neurol. 407, 130-150.

Bach, A., Lallemand, Y., Nicola, M. A., Ramos, C., Mathis, L., Maufras, M., and Robert, B. (2003). Msx is required for dorsal diencephalon patterning. Development 130, 4025-4036.

Bachy, I., Vernier, P., and Retaux, S. (2001). The LIM-homeodomain gene family in the developing Xenopus brain: conservation and divergences with the mouse related to the evolution of the forebrain. J. Neurosci. 21, 7620-7629.

Basler, K., Edlund, T., Jessell, T. M., and Yamada, T. (1993). Control of cell pattern in the neural tube: regulation of cell differentiation by dorsalin-1, a novel TGF beta family member. Cell 73, 687-702.

Basson, M. A., Echevarria, D., Ahn, C. P., Sudarov, A., Joyner, A. L., Mason, I. J., Martinez, S., and Martin, G. R. (2008). Specific regions within the embryonic midbrain and cerebellum require different levels of FGF signaling during development. Development 135, 889-898.

Bergquist, H. (1932). Zur Morphologie des Zwischenhirns bei niederen Wirbeltieren. Acta Zool. 13, 57-303.

Bergquist, H., and Kallen, B. (1954). Notes on the early histogenesis and morphogenesis of the central nervous system in vertebrates. J. Comp. Neurol. 100, 627-659.

Blackshaw, S., Scholpp, S., Placzek, N., Ingrahan, H., Simerly, R., and Simogori, T. (2010). Molecular pathways controlling divelopment of thalamus and hypothalamus: from neural specifcation to circuit formation. J. Neurosci. 30, 14925-14930. A., Robertson, C. P., and Roelink, H. (2003). Wnt signaling is required
Braun, M. M., Etheridge, A., Bernard,

development are present in different vertebrate species to regulate similar developmental processes. In this review, diencephalic anatomy and some interactions between different signaling molecules and transcription factors in diencephalic development have been analyzed, as a basic platform to get inside thalamic structural and functional complexity.

\section{ACKNOWLEDGMENTS}

This work was supported by the grants: EUCOMMTOOLS (European Commission, Contract 261492), Spanish MICINN BFU2010-27326, Spanish MICINN BFU-2008-00588, and BFU2011-27326, CONSOLIDER (CSD2007-00023).

at distinct stages of development for the induction of the posterior forebrain. Development 130, 5579-5587.

Bulfone, A., Puelles, L., Porteus, M. H. Frohman, M. A., Martin, G. R., and Rubenstein, J. L. (1993). Spatially restricted expression of Dlx-1, Dlx2 (Tes-1), Gbx-2, and Wnt-3 in the embryonic day 12.5 mouse forebrain defines potential transverse and longitudinal segmental boundaries. J. Neurosci. 13, 3155-3172.

Chapman, S. C., Brown, R., Lees, L., Schoenwolf, G. C., and Lumsden, A (2004). Expression analysis of chick Wnt and frizzled genes and selected inhibitors in early chick patterning. Dev. Dyn. 229, 668-676.

Chazaud, C., Oulad-Abdelghani, M. Bouillet, P., Décimo, D., Chambon, P., and Dollé, P. (1996). AP-2.2 a novel gene related to AP-2 is expressed in the forebrain limbs and face during mouse embryogenesis. Mech. Dev. 54, 83-94.

Chi, C. L., Martinez, S., Wurst, W., and Martin, G. R. (2003). The isthmic organizer signal FGF8 is required for cell survival in the prospective midbrain and cerebellum. Development 130, 2633-2644.

Colas, J. F., and Schoenwolf, G. C. (2001). Towards a cellular and molecular understanding of neurulation. Dev. Dyn. 221, 117-145.

Crossley, P. H., and Martin, G. R. (1995). The mouse Fgf8 gene encodes a family of polypeptides and is expressed in regions that direct outgrowth and patterning in the developing embryo. Development 121, 439-451.

Crossley, P. H., Martinez, S., and Martin, G. R. (1996). Midbrain development induced by FGF8 in the chick embryo. Nature 380, 66-68.

Davis, G. K., and Patel, N. H. (1999). The origin and evolution of segmentation. Trends Cell Biol. 9, M68-M72.

De Robertis, E., Morita, E. A., and Cho, K. W. (1991). Gradient fields and homeobox genes. Development 112, 669-678.
Delaunay, D., Heydon, K., Miguez, A., Schwab, M., Nave, K. A., Thomas, J. L., Spassky, N., Martinez, S., and Zalc, B. (2009). Genetic tracing of subpopulation neurons in the prethalamus of mice (Mus musculus). J. Comp. Neurol. 512, 74-83.

Dickinson, M., Selleck, M. A., McMahon, A. P., and Bronner-Fraser, M. (1995). Dorsalization of the neural tube by the non-neural ectoderm. Development 121, 2099-2106.

Dickinson, M. E., and McMahon, A. P. (1992). The role of Wnt genes in vertebrate development. Curr. Opin. Genet. Dev. 2, 562-566.

Diez-Roux, G., Banfi, S., Sultan, M., Geffers, L., Anand, S., Rozado, D., Magen, A., Canidio, E., Pagani, M., Peluso, I., Lin-Marq, N., Koch, M., Bilio, M., Cantiello, I., Verde, R., De Masi, C., Bianchi, S. A., Cicchini, J., Perroud, E., Mehmeti, S., Dagand, E., Schrinner, S., Nürnberger, A., Schmidt, K., Metz, K., Zwingmann, C., Brieske, N., Springer, C., Hernandez, A. M., Herzog, S., Grabbe, F., Sieverding, C., Fischer, B., Schrader, K., Brockmeyer, M., Dettmer, S., Helbig, C., Alunni, V., Battaini, M. A., Mura, C., Henrichsen, C. N., GarciaLopez, R., Echevarria, D., Puelles, E., Garcia-Calero, E., Kruse, S., Uhr, M., Kauck, C., Feng, G., Milyaev, N., Ong, C. K., Kumar, L., Lam, M., Semple, C. A., Gyenesei, A., Mundlos, S., Radelof, U., Lehrach, H., Sarmientos, P., Reymond, A., Davidson, D. R., Dollé, P., Antonarakis, S. E., Yaspo, M. L., Martinez, S., Baldock, R. A., Eichele, G., and Ballabio, A. (2011). A high-resolution anatomical atlas of the transcriptome in the mouse embryo. PLoS Biol. 9, e1000582. doi:10.1371/journal.pbio.1000582

Domínguez, L., González, A., and Moreno, N. (2010). Sonic hedgehog expression during Xenopus laevis forebrain development. Brain Res. 1347, 19-32.

Echelard, Y., Epstein, D. J., St-Jacques, B., Shen, L., Mohler, J., McMahon, 
S. A., and McMahon, A. P. (1993). Sonic hedgehog, a member of a family of putative signaling molecules, is implicated in the regulation of CNS polarity. Cell 75, 1417-1430.

Echevarria, D., Vieira, C., Gimeno, L., and Martinez, S. (2003). Neuroepithelial secondary organizers and cell fate specification in the developing brain. Brain Res. Rev. 43, 179-191.

Falcón, J., Besseau, L., Fuentès, M., Sauzet, S., Magnanou, E., and Boeuf, G. (2009). Structural and functional evolution of the pineal melatonin system in vertebrates. Ann. N. Y. Acad. Sci. 1163, 101-111.

Ferran, J. L., de Oliveira, E. D., Merchán, P., Sandoval, J. E., Sánchez-Arrones, L., Martinez-de-la-Torre, M., and Puelles, L. (2009). Genoarchitectonic profile of developing nuclear groups in the chicken pretectum. J. Comp. Neurol. 517, 405-451.

Ferran, J. L., Sánchez-Arrones, L., Bardet, S. M., Sandoval, J. E., Martinez-de-la-Torre, M., and Puelles, L. (2008). Early pretectal gene expression pattern shows a conserved anteroposterior tripartition in mouse and chicken. Brain Res. Bull. 75, 295-298.

Figdor, M. C., and Stern, C. D. (1993). Segmental organization of embryonic diencephalon. Nature 363, 630-634.

Garcia-Lopez, R., Vieira, C., Echevarria, D., and Martinez, S. (2004). Fate map of the diencephalon and the zona limitans at the 10-somites stage in chick embryos. Dev. Biol. 268, 514-530.

Garda, A. L., Puelles, L., Rubenstein, J. L. R., and Medina, L. (2002). Expression patterns of Wnt8b and Wnt7b in the chicken embryonic brain suggest a correlation with forebrain patterning centers and morphogenesis. Neuroscience 113, 689-698.

Garel, S., Marín, F., Mattéi, M. G., Vesque, C., Vincent, A., and Charnay, P. (1997). Family of Ebf/Olf-1 -related genes potentially involved in neuronal differentiation and regional specification in the central nervous system. Dev. Dyn. 210, 191-205.

Gilbert, S. F. (2010). Developmental Biology, 9th Edn. Sunderland: Sinauer Associates, Inc.

Gimeno, L., Brûlet, P., and Martinez, S. (2003). Study of Fgf15 gene expression in developing mouse brain. Gene Expr. Patterns 3, 473-481.

Hashimoto-Torii, K., Motoyama, J., Hui, C. C., Kuroiwa, A., Nakafuku, M., and Shimamura, K. (2003). Differential activities of Sonic hedgehog mediated by Gli transcription factors define distinct neuronal subtypes in the dorsal thalamus. Mech. Dev. 120, 1097-1111.

Herrick, C. J. (1910). The morphology of the forebrain in amphibia and reptilia. J. Comp. Neurol. 20, 413-547.

Hikosaka, O., Sesack, S. R., Lecourtier, L., and Shepard, P. D. (2008). Habenula: crossroad between the basal ganglia and the limbic system. J. Neurosci. 28, 11825-11829.

Hirata, T., Nakazawa, M., Muraoka, O., Nakayama, R., Suda, Y., and Hibi, M. (2006). Zinc-finger genes Fez and Fez-like function in the establishment of diencephalon subdivisions. Development 133, 3993-4004.

Houart, C., Westerfield, M., and Wilson, S. W. (1998). A small population of anterior cells patterns the forebrain during zebrafish gastrulation. Nature 391, 788-792.

Irving, C., and Mason, I. (1999). Regeneration of isthmic tissue is the result of a specific and direct interaction between rhombomere 1 and midbrain. Development 126, 3981-3989.

Jeong, Y., Dolson, D. K., Waclaw, R. R., Matise, M. P., Sussel, L., Campbell, K., Kaestner, K. H., and Epstein, D. J. (2011). Spatial and temporal requirements for sonic hedgehog in the regulation of thalamic interneuron identity. Development 138, 531-541.

Jeong, Y., El-Jaick, K., Roessler, E., Muenke, M., and Epstein, D. J. (2006). A functional screen for sonic hedgehog regulatory elements across a $1 \mathrm{Mb}$ interval identifies long-range ventral forebrain enhancers. Development 133, 761-772.

Jessell, T. M., and Sanes, J. R. (2000). Development. The decade of the developing brain. Curr. Opin. Neurobiol. 10, 599-611.

Jones, E. G. (2006). The Thalamus Revisited. Cambridge: Cambridge University Press.

Kataoka, A., and Shimogori, T. (2008). Fgf8 controls regional identity in the developing thalamus. Development 135, 2873-2881.

Keyser, A. (1972). The development of the diencephalon of the Chinese hamster. An investigation of the validity of the criteria of subdivision in the brain. Acta Anat. Suppl. (Basel) 83, 1-181.

Kiecker, C., and Lumsden, A. (2005). Compartments and their boundaries in vertebrate brain development. Nat. Rev. Neurosci. 7, 553-564.

Kingsley, D. (1994). The TGF-beta superfamily: new members, new receptors, and new genetic tests of function in different organisms. Genes Dev. 8, 133-146.

Kobayashi, D., Kobayashi, M., Matsumoto, K., Ogura, T., Nakafuku, M., and Shimamura, K. (2002). Early subdivisions in the neural plate define distinct competence for inductive signals. Development 129, 83-93.

Larsen, C. W., Zeltser, L. M., and Lumsden, A. (2001). Boundary formation and compartition in the avian diencephalon. J. Neurosci. 21, 4699-4711.

Lavado, A., Lagutin, O. V., and Oliver, G. (2008). Six 3 inactivation causes progressive caudalization and aberrant patterning of the mammalian diencephalon. Development 135, 441-450.

Lee, K. J., and Jessell, T. M. (1999). The specification of dorsal cell fates in the vertebrate central nervous system. Annu. Rev. Neurosci. 22, 261-294.

Liem, K. F. J., Tremml, G., Roelink, H., and Jessell, T. M. (1995). Dorsal differentiation of neural plate cells induced by BMP-mediated signals from epidermal ectoderm. Cell 82, 969-979.

Martinez, S. (2001). The isthmic organizer and brain regionalization. Int J. Dev. Biol. 45, 367-3771.

Martinez, S., Crossley, P. H., Cobos, I. Rubenstein, J. L., and Martin, G. R. (1999). FGF8 induces formation of an ectopic isthmic organizer and isthmocerebellar development via a repressive effect on Otx2 expression. Development 126, 1189-1200.

Martinez, S., Puelles, E., Puelles, L. and Echevarria, D. (2012). "Molecular regionalization of the developing neural tube," in The Mouse Nervous System, eds C. Watson, G. Paxinos, and L. Puelles (London: Academic Press, Elsevier), 2-18.

Martinez, S., and Puelles, L. (2000) Neurogenetic compartments of the mouse diencephalon and some characteristic gene expression patterns Results Probl. Cell Differ. 30, 91-106.

Martinez-de-la-Torre, M., Garda, A. L., Puelles, E., and Puelles, L. (2002). Gbx2 expression in the late embryonic chick dorsal thalamus. Brain Res. Bull. 57, 435-438.

Martinez-Ferre, A., and Martinez, S. (2009). The development of the thalamic motor learning area is regulated by Fgf8 expression. J. Neurosci. 29, 13389-13400.

Matsumoto, M., and Hikosaka, O. (2008). Negative motivational control of saccadic eye movement by the lateral habenula. Prog. Brain Res. 171, 399-402.

Matsumoto, M., and Hikosaka, O. (2009). Representation of negative motivational value in the primate lateral habenula. Nat. Neurosci. 12, 77-84.

Mattes, B., Weber, S., Peres, J., Chen, Q., Davidson, G., Houart, C., and Scholpp, S. (2012). Wnt3 and Wnt3a are required for induction of the mid-diencephalic organizer in the caudal forebrain. Neural Dev. 7, 12.

Mitrofanis, J., and Baker, G. E. (1993). Development of reticular and perireticular nucleus in rats and their relationship to the course of growing corticofugal and corticopetal axons. J. Comp. Neurol. 338, 575-587.

Mueller, T., Vernier, P., and Wullimann, M. F. (2006). A phylotypic stage in vertebrate brain development: GABA cell patterns in zebrafish compared with mouse. J. Comp. Neurol. 494, 620-634.

Nieuwenhuys, R. (1998) "Morphogenesis and general structures," in The Central Nervous System of Vertebrates, Vol. 1, eds R. Nieuwenhuys, H. J. Ten Donkelaar, and C. Nicholson (Berlin: Springer-Verlag), 158-228.

Nieuwenhuys, R. (1999). The morphological pattern of the vertebrate brain. Eur. J. Morphol. 37, 81-84.

Nieuwenhuys, R. (2011). The structural, functional, and molecular organization of the brainstem. Front. Neuroanat. 5:33. doi:10.3389/fnana.2011.00033

Oliver, G., Mailhos, A., Wehr, R., Copeland, N. G., Jenkins, N. A., and Gruss, P. (1995). Six3, a murine homologue of the sine oculis gene, demarcates the most anterior border of the developing neural plate and is expressed during eye development. Development 121, 4045-4055.

Osório, J., Mueller, T., Rétaux, S. Vernier, P., and Wullimann, M. F. (2010). Phylotypic expression of the bHLH genes Neurogenin2, Neurod, and Mash1 in the mouse embryonic forebrain. J. Comp. Neurol. 518, 851-871.

Parr, B. A., Shea, M. J., Vassileva, G., and McMahon, A. (1993). Mouse Wnt genes exhibit discrete domains of expression in the early embryonic CNS and limb buds. Development 119, 247-261.

Peukert, D., Weber, S., Lumsden, A., and Scholpp, S. (2011). Lhx2 and Lhx9 determine neuronal differentiation and compartition in the caudal forebrain by regulating Wnt signaling. PLoS Biol. 9, e1001218. doi:10.1371/journal.pbio.1001218

Price, M., Lazzaro, D., Pohl, T., Mattei, M. G., Rüther, U., Olivo, J. C., Duboule, D., and Di Lauro, R. (1992). Regional expression of 
the homeobox gene Nkx-2.2 in the developing mammalian forebrain. Neuron 8, 241-255.

Puelles, L. (2001). Brain segmentation and forebrain development in amniotes. Brain Res. Bull. 55, 695-710.

Puelles, L., Amat, J. A., and Martinezde-la-Torre, M. (1987). Segmentrelated, mosaic neurogenetic pattern in the forebrain and mesencephalon of early chick embryos: I. Topography of AChE-positive neuroblasts up to stage HH18. J. Comp. Neurol. 266, 247-268.

Puelles, L., Javier Milán, F., and Martinez-de-la-Torre, M. (1996). A segmental map of architectonic subdivisions in the diencephalon of the frog Rana perezi: acetylcholinesterase-histochemical observations. Brain Behav. Evol. 47, 279-310.

Puelles, L., Martinez, S., and Martinezde-la-Torre, M. (2008). Neuronatomia. Buenos Aires: Panamericana.

Puelles, L., Martínez, S., Martínez-de-laTorre, M., and Rubenstein, J. L. R. (2004). "Gene maps and related histogenetic domains in the forebrain and midbrain," in The Rat Nervous System, 3rd Edn, ed. G. Paxinos (San Diego: Academic Press), 3-25.

Puelles, L., Martínez-de-la-Torre, M., Paxinos, G., Watson, C. H., and Martínez, S. (2007). The Chick Brain in Stereotaxic Coordinates. An Atlas Featuring Neuromeric Subdivisions and Mammalian Homologues, 1st Edn. San Diego: Academic Press, Elsevier.

Puelles, L., Martinez-de-la-Torre, M., Bardet, S., and Rubenstein, J. L. R. (2012). "Diencephalon," in The Mouse Nervous System, eds C. Watson, G. Paxinos, and L. Puelles (London: Academic Press, Elsevier), 313-336.

Puelles, L., and Rubenstein, J. L. (2003). Forebrain gene expression domains and the evolving eic model. Trends Neurosci. 9, 469-476.

Puelles, L., and Rubenstein, J. L. (1993). Expression patterns of homeobox and other putative regulatory genes in the embryonic mouse forebrain suggest a neuromeric organization. Trends Neurosci. 16, 472-479.

Quinlan, R., Graft, M., Mason, I., Lumsden, A., and Kiecker, C. (2009). Complex and dynamic patterns of Wnt pathway gene expression in the developing chick forebrain. Neural Dev. 4, 4-35.

Redies, C. (1995). Cadherin expression in the developing vertebrate CNS: from neuromeres to brain nuclei and neural circuits. Exp. Cell Res. 220, 243-256.
Redies, C. (2000). Cadherins in the central nervous system. Prog. Neurobiol. 61, 611-648.

Redies, C., Arndt, K., and Ast, M. (1997). Expression of the cell adhesion molecule axonin-1 in neuromeres of the chicken diencephalon. J. Comp. Neurol. 381, 230-252.

Redies, C., Ast, M., Nakagawa, S., Takeichi, M., Martinez-de-la-Torre, M., and Puelles, L. (2000). Morphologic fate of diencephalic prosomeres and their subdivisions revealed by mapping cadherin expression. J. Comp. Neurol. 421, 481-514.

Redies, C., and Takeichi, M. (1996). Cadherins in the developing central nervous system: an adhesive code for segmental and functional subdivisions. Dev. Biol. 180, 413-423.

Rendahl, H. (1924). Embryologische und morphologische. Studies über das Zwischenhirn beim Huhn. Acta Zool. 5, 241-344.

Rubenstein, J. L., Martinez, S., Shimamura, K., and Puelles, L. (1994). The embryonic vertebrate forebrain: the prosomeric model. Science 266, 578-580.

Sanchez-Arrones, L., Stern, C. D., Bovolenta, P., and Puelles, L. (2012). Sharpening of the anterior neural border in the chick by rostral endoderm signalling. Development 139 , 1034-1044.

Sato, T., and Joyner, A. L. (2009). The duration of Fgf8 isthmic organizer expression is key to patterning different tectal-isthmo-cerebellum structures. Development 136, 3617-3626.

Scholpp, S., and Lumsden, A. (2010) Building a bridal chamber: development of the thalamus. Trends Neurosci. 33, 373-380.

Scholpp, S., Wolf, O., Brand, M., and Lumsden, A. (2006). Hedgehog signaling from the zona limitans intrathalamica orchestrates patterning of the zebrafish diencephalon. Development 133, 855-864.

Shimamura, K., Hartigan, D. J., Martinez, S., Puelles, L., and Rubenstein, J. L. R. (1995). Longitudinal organization of the anterior neural plate and neural tuve. Development 121, 3923-3933.

Shimamura, K., and Rubenstein, J. L. R. (1997). Inductive interactions direct early regionalization of the mouse forebrain. Development 124, 2709-2718.

Shimogori, T., Lee, D. A., MirandaAngulo, A., Yang, Y., Wang, H., Jiang, L., Yoshida, A. C., Kataoka, A., Mashiko, H., Avetisyan, M., Qi, L., Qian, J., and Blackshaw, S. (2010). A genomic atlas of mouse hypothalamic development. Nat. Neurosci. 13, 767-775.
Simeone, A., Acampora, D., Gulisano, M., Stornaiuolo, A., and Boncinelli, E. (1992). Nested expression domains of four homeobox genes in developing rostral brain. Nature 358, 687-690.

Simeone, A., Acampora, D., Mallamaci, A., Stornaiuolo, A., D’Alpice, M. R., Nigro, V., and Boncinelli, E. (1993). A vertebrate gene to orthodenticle contains a homeodomain of the bicoid class and demarcates anterior neuroectoderm in the gastrulating mouse embryo. EMBO J. 12 , 2735-2747.

Staudt, N., and Houart, C. (2007) The prethalamus is established during gastrulation and influences diencephalic regionalization. PLoS Biol. 5, e69. doi:10.1371/journal.pbio.0050069

Stoykova, A., and Gruss, P. (1994). Roles of Pax-genes in developing and adult brain as suggested by expression patterns. J. Neurosci. 14, 1395-1412.

Suzuki-Hirano, A., Ogawa, M., Kataoka, A., Yoshida, A. C., Itoh, D., Ueno, M., Blackshaw, S., and Shimogori, T. J. (2010). Dynamic spatiotemporal gene expression in embryonic mouse thalamus. J. Comp. Neurol. 519, 528-543.

Swanson, L. W. (2003). Brain Architecture. Oxford, NY: Oxford University Press.

Szabó, N. E., Zhao, T., Zhou, S., and Alvarez-Bolado, G. (2009). The role of Sonic hedgehog of neural origin in thalamic differentiation in the mouse. J. Neurosci. 29, 2453-2466.

Ten Tusscher, K. H., and Hogeweg, P. (2011). Evolution of networks for body plan patterning; interplay of modulary robustness and evolvability. Plos Comput. Biol. 7, e1002208. doi:10.1371/journal.pcbi.1002208

Ulfig, N., Neudörfer, F., and Bohl, J. (2000). Transient structures of the human fetal brain: subplate, thalamic reticular complex, ganglionic eminence. Histol. Histopathol. 15. 771-790.

Vieira, C., Garda, A. L., Shimamura, K., and Martinez, S. (2006). Thalamic development induced by Shh in the chick embryo. Dev. Biol. 284, 351-363.

Vieira, C., and Martinez, S. (2006). Sonic hedgehog from the basal plate and the zona limitans intrathalamica exhibits differential activity on diencephalic molecular regionalization and nuclear structure. Neuroscience 143, 129-140.

Vieira, C., Pombero, A., García-Lopez R., Gimeno, L., Echevarria, D., and Martinez, S. (2010). Molecular mechanisms controlling brain development: an overview of neuroep- ithelial secondary organizers. Int. J. Dev. Biol. 54, 7-20.

Vue, T. Y., Bluske, K., Alishahi, A., Yang, L. L., Koyano-Nakagawa, N. Novitch, B., and Nakagawa, Y. (2009). Sonic hedgehog signaling controls thalamic progenitor identity and nuclei specification in mice. J. Neurosci. 29, 4484-4497.

Walshe, J., and Mason, I. (2003). Unique and combinatorial functions of Fgf3 and Fgf8 during zebrafish forebrain development. Development 130, 4337-4349.

Wassarman, K. M., Lewandoski, M., Campbell, K., Joyner, A. L., Rubenstein, J. L., Martinez, S., and Martin, G. R. (1997). Specification of the anterior hindbrain and establishment of a normal mid/hindbrain organizer is dependent on Gbx2 gene function. Development 124, 2923-2934.

Wullimann, M. F., and Muller, T. (2004). Identification and morphogenesis of eminentia thalami in the zebrafish. $J$. Comp. Neurol. 471, 37-48.

Wullimann, M. F., and Puelles, L. (1999). Postembryonic neural proliferation in the zebrafish and its relationship to prosomeric model. Anat. Embryol. 199, 329-348.

Zeltser, L. M. (2005). Shh-dependent formation of the ZLI is opposed by signals from the dorsal diencephalon. Development 132, 2023-2033.

Zeltser, L. M., Larsen, C. W., and Lumsden, A. (2001). A new developmental compartment in the forebrain regulated by Lunatic fringe. Nat. Neurosci. 7, 683-684.

Conflict of Interest Statement: The authors declare that the research was conducted in the absence of any commercial or financial relationships that could be construed as a potential conflict of interest.

Received: 06 February 2012; paper pending published: 13 February 2012; accepted: 03 May 2012; published online: 25 May 2012.

Citation: Martinez-Ferre A and Martinez $S$ (2012) Molecular regionalization of the diencephalon. Front. Neurosci. 6:73. doi: 10.3389/fnins.2012.00073

This article was submitted to Frontiers in Neurogenesis, a specialty of Frontiers in Neuroscience.

Copyright (c) 2012 Martinez-Ferre and Martinez. This is an open-access article distributed under the terms of the Creative Commons Attribution Non Commercial License, which permits noncommercial use, distribution, and reproduction in other forums, provided the original authors and source are credited. 